\title{
Drainage ditch extraction from airborne LiDAR point clouds
}

\author{
Jennifer Roelens ${ }^{\mathrm{a}, *}$, Bernhard Höfle ${ }^{\mathrm{b}}$, Stefaan Dondeyne ${ }^{\mathrm{a}}$, Jos Van Orshoven ${ }^{\mathrm{a}}$, Jan Diels ${ }^{\mathrm{a}}$ \\ a Department of Earth \& Environmental Sciences, KU Leuven, Celestijnenlaan 200E - Box 2411, B-3001 Leuven, Belgium \\ b Department of Geography, 3D Geo Research Group, Heidelberg University, Heidelberg, Germany
}

A R T I C L E I N F O

\section{Keywords:}

LiDAR

Point cloud

Signal intensity

Ditch

Classification

Dropout

\begin{abstract}
A B S T R A C T
Ditches are often absent in hydrographic geodatasets and their mapping would benefit from a cost and labor effective alternative to field surveys. We propose and evaluate an alternative that makes use of a high resolution LiDAR point cloud dataset. First the LiDAR points are classified as ditch and non-ditch points by means of a random forest classifier which considers subsets of the topographic and radiometric features provided by or derived from the LiDAR product. The LiDAR product includes for each georeferenced point, the elevation, the returned intensity value, and RGB values from simultaneously acquired aerial images. Next so-called ditch dropout points are reconstructed for the blind zones in the dataset using a new geometric approach. Finally, LiDAR ditch points and dropouts are assembled into ditch objects (2D-polygons and their derived centre lines). The procedure was evaluated for a grassland and a peri-urban agricultural area in Flanders, Belgium. A good point classification was obtained (Kappa $=0.77$ for grassland and 0.73 for peri-urban area) by using all the features derived from the LiDAR product, whereby the geometric features had the greatest influence. However, even better results were obtained when the radiometric component of the LiDAR product was also taken into account. For the tested models for the extraction of ditch centre lines, the best resulted in an error of omission of 0.03 and an error of commission of 0.08 for the grassland study area and an error of omission of 0.14 and an error of commission of 0.07 for the peri-urban study area.
\end{abstract}

\section{Introduction}

Anthropogenic ditches are common landscape features in temperate and boreal landscapes to extend and modify the natural drainage networks (Duke et al., 2006; Levavasseur et al., 2014). The density of open artificial drainage ditches in the lowlands of Western Europe is highly variable reaching $200-300 \mathrm{~m} / \mathrm{ha}$, and is related to the type of human activities such as agriculture, urbanization or infrastructure development (Bailly et al., 2008; Lagacherie et al., 2006; Levavasseur et al., 2014; Rapinel et al., 2015; Roelens et al., 2018; Sofia et al., 2014). Ditches control water and solute fluxes and hence contribute to regulating ecosystem services when managed properly. They play a role in flood control, biochemical cycles, erosion control and biodiversity conservation (Bailly et al., 2008; Buchanan et al., 2013; Carluer and De Marsily, 2004; Dages et al., 2009; Dollinger et al., 2015; Herzon and Helenius, 2008; Levavasseur et al., 2014; Moussa et al., 2002; Rouquette et al., 2011).

Ditch networks are increasingly being incorporated in spatially distributed water and solute runoff models as they strongly impact runoff (Carluer and De Marsily, 2004; Levavasseur et al., 2010; Moussa et al., 2002). Hence the appropriateness of measures and management decisions derived from such models benefit from high quality spatial information about the presence, characteristics and functioning of ditches (Andersson et al., 2015; Carluer and De Marsily, 2004; Cavalli, 2013; Cazorzi et al., 2013; Levavasseur et al., 2010; Moussa et al., 2002).

For the Flemish region in Belgium, georeferenced information on water courses is stored in the Flemish Hydrographic Atlas (Vlaamse Hydrografische Atlas, VHA) and in the Large-Scale Reference Database for Flanders (Grootschalig referentiebestand, GRB). For the VHA, water courses were digitized from topographic maps derived from aerial photographs older than 1992 and published at a cartographic scale of 1:10,000 (Integraal Waterbeleid, 2014). The positional quality and completeness of this dataset is impacted by the resolution limitations of the source imagery (spatial resolution of $1 \mathrm{~m}$, AGIV (2015a)), the scale of printing and errors related to conversion from analogue to digital media. The VHA is furthermore incomplete for smaller hydrographic elements, and particularly so for drainage ditches, as at that time, little importance was attached to them in the context of topographic mapping (Bailly et al., 2008; Rapinel et al., 2015). For $70 \%$ of the mapped

\footnotetext{
* Corresponding author at: KU Leuven (University of Leuven), Department of Earth and Environmental Sciences, Celestijnenlaan 200E - Box 2411, B-3001 Leuven, Belgium.

E-mail address: jennifer.roelens@kuleuven.be (J. Roelens).
} 
water courses (lines) in the VHA, information on their perimeter (polygons) can be found in the GRB. Furthermore, the GRB contains information on the trajectory of roadside ditches and some other smaller water courses (lines), however this data is not complete. Additionally, both reference datasets lack information on agricultural drainage ditches.

An alternative data source to aerial photography and ground-based measurements for mapping drainage ditches are three-dimensional point clouds (X-Y-Z) produced by airborne light detection and ranging (LiDAR or laser mapping) systems. LiDAR point clouds and the derived Digital Elevation Models (DEM) have been used for detecting ditches (Bailly et al., 2008; Broersen et al., 2017; Cazorzi et al., 2013; Liimatainen et al., 2015; Passalacqua et al., 2012; Rapinel et al., 2015; Roelens et al., 2018; Sangireddy et al., 2016; Shore et al., 2013), estimating water levels in water courses, and for determining channel and ditch morphologies (Caroti et al., 2014; Dietterick et al., 2012; Hopkinson et al., 2011; Magirl et al., 2005; Podhoranyi and Fedorcak, 2015; Roelens et al., 2016; Roub et al., 2012).

Most of the current LiDAR-based ditch extraction methods do not use the original LiDAR point clouds but rather start from derived rasterized digital elevation models (DEM). The creation of a raster based DEM leads, however, to a degradation of the spatial resolution of the original point cloud (Bailly et al., 2008). Höfle and Rutzinger (2011) reported advances by directly analysing three-dimensional point clouds to maintain the highest degree of information without prior filtering and interpolating the elevation measurements. A first application of point clouds for ditch extraction was reported by Bailly et al. (2008). These authors used point clouds to extract cross-sectional profiles at known locations of agricultural field boundaries and classified them as a ditch or non-ditch based on the curvature. Broersen et al. (2017) proposed a more advanced method for processing point clouds for ditch detection without the need of ancillary data. These authors took advantage of the absence of LiDAR points on water surfaces and of the concavities in the landscape. Unfortunately, the results of this study were compromised by the presence of large patches of vegetation that cover water bodies, and the presence of voids in the LiDAR point cloud that were not coinciding with water bodies. Another limitation was the sole dependence on surface curvature leading to finding concavities in the landscape where one would not immediately expect a watercourse, e.g. levees or piles of soil or dirt (Broersen et al., 2017). A way to avoid these errors could be by using additional complementary information that is available through processing and analysis of airborne 3D LiDAR products. Airborne 3D LiDAR products include for each georeferenced point, elevation data (XYZ), returned intensity values, RGB values from simultaneously acquired aerial images, a classification value and additional scanning parameters.

Airborne LiDAR data for target classification and recognition can be processed using the DEM or the LiDAR points directly. Hartfield et al. (2011) classified raster cells for different types of land cover by combining LiDAR elevation, LiDAR intensity and RGB-reflectance. Brzank and Heipke (2006), Höfle et al. (2009) and Malinowski et al. (2016) developed LiDAR point classification methods based on local 3D surface descriptors and LiDAR intensity to delineate water bodies and floodplains. Automatically assigning 3D points a semantic class label has become an important topic in photogrammetry, remote sensing, computer vision and robotics. Weinmann (2016) considered a general processing workflow for 3D scene analysis consisting of four components: neighbourhood selection, feature extraction, feature selection and classification. This workflow allows testing different features for their influence on the quality of classification. Such classification of LiDAR points as an aid to ditch network extraction has so far not been attempted.

The first objective of this study was to determine with which accuracy dropouts in the point clouds that are the result of the absorption of the laser signal by water can be geometrically reconstructed (cf. Höfle et al., 2009). The second objective was to evaluate the applicability of Weinmann's methodology (2016) for classification of LiDAR points as ditch or non-ditch using features derived from the individual LiDAR point information or from information of a set of points in a neighbourhood. As part of pursuing this objective, subsets and individual features were evaluated on their importance for classification. A third objective was to evaluate the ditch object building approach (2D polygons and centre lines) starting from the classified points. Finally, the aim was to evaluate the developed methods for two contrasting study sites, a grassland area and a peri-urban agricultural area, both located in the Flemish region of Belgium.

\section{Study areas and available data}

\subsection{Study areas}

The first study area (SA1) is a grassland area located in the alluvial valley of the Dyle river, $c a$. $20 \mathrm{~km}$ east of Brussels in central Belgium. It is part of the nature reserve 'de Doode Bemde' that has an extensive network of drainage ditches dating back to the 18th and 19th century which were intended to turn back swamps into meadows. Distinct zones of secondary vegetation can be found with reed beds in the centre of the wetland and a gradient of large sedge scrubland and tall-herb fen to a fen meadow type and eventually shine oat grassland on the drier levees (Joris and Feyen, 2003; Vercoutere, 2014). The total length of the ditches in SA1 is approximately $3 \mathrm{~km}$ in an area of $10.3 \mathrm{ha}$ (Fig. 1, left). The elevation of SA1 ranges between $26.4 \mathrm{~m}$ and $27.9 \mathrm{~m}$ a.s.1.

The second study area (SA2) is a peri-urban area located in the alluvial valley of the Demer river in north-eastern Belgium. The study area contains more different landscape elements, and the land use mainly consists of cropland, with varying types of crops, and pastures. The drainage ditches in this area also date back to the 18th century but were mainly created for arable land (Agentschap Onroerend Erfgoed, 2013). The total length of the ditches in SA2 is approximately $18 \mathrm{~km}$ in an area of 150 ha (Fig. 1, right). The elevation in SA2 ranges between $30.1 \mathrm{~m}$ and $39.7 \mathrm{~m}$ a.s.l. The main difference between the two study areas is that over the last decades SA1 has been converted into a nature reserve with minimal maintenance of the drainage system while SA2 still is still used for intensive agricultural activities with a functional, reasonably well maintained drainage system. Nevertheless, the maintenance of culverts is often lacking.

\subsection{Reference data}

The trajectories of the ditches were measured in the field in August 2015 for SA1 and September-October 2016 for SA2. For SA1, the centre lines and banks of the ditches were measured with a real time kinematic (RTK) GPS device (Trimble 5800 model) with a nominal horizontal accuracy of $0.01 \mathrm{~m}$ (RMSExy) and a vertical accuracy of $0.02 \mathrm{~m}$ (RMSEz) (Trimble Navigation Limited, 2005). The real-time correction was done using the reference stations network of the Flemish Positioning Service (FLEPOS, http://ntrip.flepos.be/). For SA2, the centrelines of the ditches were recorded using a hand-held Trimble GeoExplorer XT GNSS and were differentially post-processed to obtain a sub-meter horizontal accuracy.

Reference data on the perimeters of the ditches, i.e. polygons corresponding to the ditch banks, were created for SA1 using the RTK measured banks. For SA2, no banks were measured in the field. Instead, the banks were extracted from the LiDAR point cloud using an approach designed by Roelens et al. (2016) for the automated extraction of cross sections. The modelled banks were then used to create reference ditch polygons.

\subsection{Airborne LiDAR data}

Airborne LiDAR data and digital aerial RGB images with a spatial resolution of $0.10 \mathrm{~m}$ were simultaneously acquired for the entire 


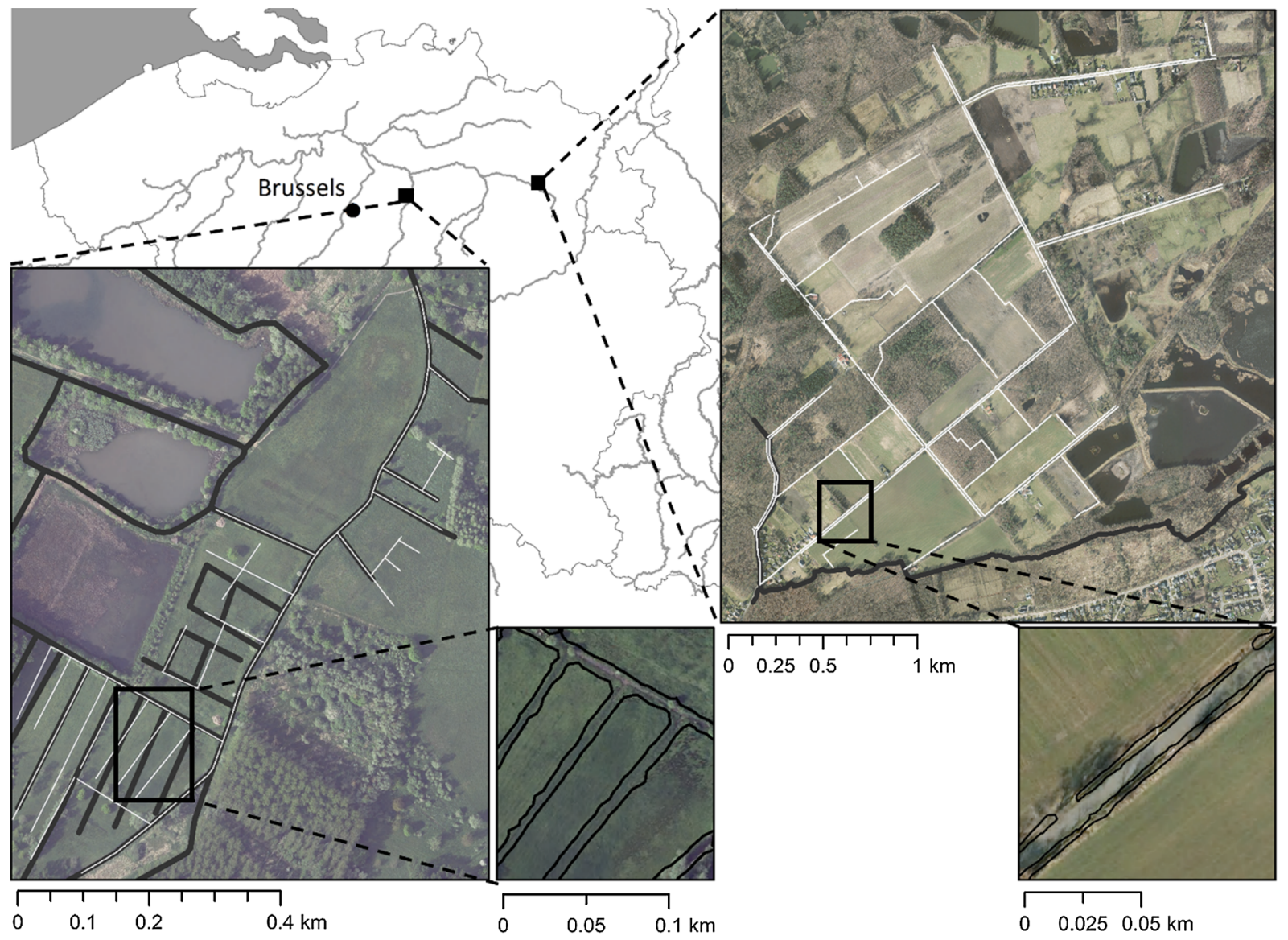

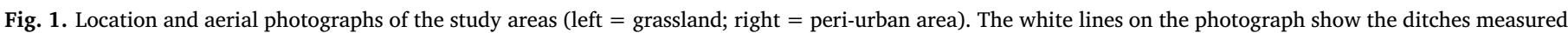

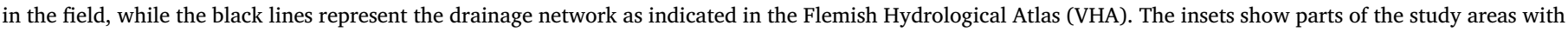
the $2 \mathrm{D}$ polygon ditch object building results (Section 3.5).

Table 1

Information on flight campaigns and number of flight lines and ground points in the different study areas.

\begin{tabular}{llll}
\hline Study area & Flight campaign date & Flight lines & Ground points \\
\hline SA1 & $02 / 03 / 2014$ & 3 & $1,472,419$ \\
& $30 / 03 / 2014$ & 1 & 229,452 \\
SA2 & $03 / 11 / 2015$ & 15 & $28,586,731$ \\
\hline
\end{tabular}

Flemish region of Belgium (13,512 $\left.\mathrm{km}^{2}\right)$ in the winter seasons of 2013, 2014 or 2015. Both types of data were collected by two private companies and their processed LiDAR products were made available by the Agency of Geographical information of Flanders (https:// remotesensing.vlaanderen.be/apps/openlidar/). Information on the flight campaigns for the study areas can be found in Table 1. The LiDAR product is available in a LAS 1.4 format and contains for each point topographic data (XYZ), the returned intensity, the assigned RGB values, a classification value and additional scanning parameters. The laser scanner was capable of recording up to five returns from each pulse. From the topographic data, outliers were removed and a LiDAR point classification in terms of 'ground level', 'non-ground level' and 'water' was done using an iterative algorithm of the Terrascan software, followed by manual quality checks and (semi-) automatic adjustments. For the simultaneously collected aerial images, the data providers supplied camera calibration reports of the non-georeferenced raw images and used these for the creation of a spectrally normalized orthophoto mosaic. The RGB colour values of the corresponding pixel in the orthophoto mosaic were assigned to each LiDAR point.

The final spatial point distribution was rather homogeneous with at least 16 points per square meter and a maximum planimetric distance (MPPD) between two points of $0.5 \mathrm{~m}$. The point cloud was furthermore subjected to a strict quality control, both planimetrically $($ RMSExy $=0.10 \mathrm{~m})$ and altimetrically $(\mathrm{RMSEz}=0.05 \mathrm{~m})$, relative to the geodetic network (Vanderstraete, 2013). The laser scanning device was the RIEGL LMS-Q680i, with a laser beam in the NIR wavelength range (at $1550 \mathrm{~nm}$ ). For each reflected echo signal, a 16-bit intensity measurement was available. The instrument had a laser pulse repetition rate up to $400,000 \mathrm{~Hz}$, a beam divergence smaller or equal to $0.5 \mathrm{mil}-$ liradians and a scan angle range of $60^{\circ}\left(-30^{\circ}\right.$ to $\left.30^{\circ}\right)$ (Petrie, 2011; Schechtner, 2012). For this study, only points that were labelled as 'ground' and 'water' were selected. These points, together with all attributes available in the LiDAR product, are further referred to as LiDAR points. Furthermore, based on the reference ditch polygons created in Section 2.2, the corresponding LiDAR points were assigned a reference ditch class label.

\section{Methodology}

The overall workflow for ditch detection consisted of the following steps: (1) radiometric correction of the LiDAR data, (2) LiDAR dropout modelling, (3) feature extraction from the LiDAR point clouds, (4) classification of the LiDAR points into a ditch and non-ditch class, (5) ditch object building from the classified ditch points and (6) evaluation. Steps (1)-(4) were done per flight campaign and the intermediate results were then combined for step (5). The workflow steps are shown in Fig. 2 and described in detail in the following subsections. 


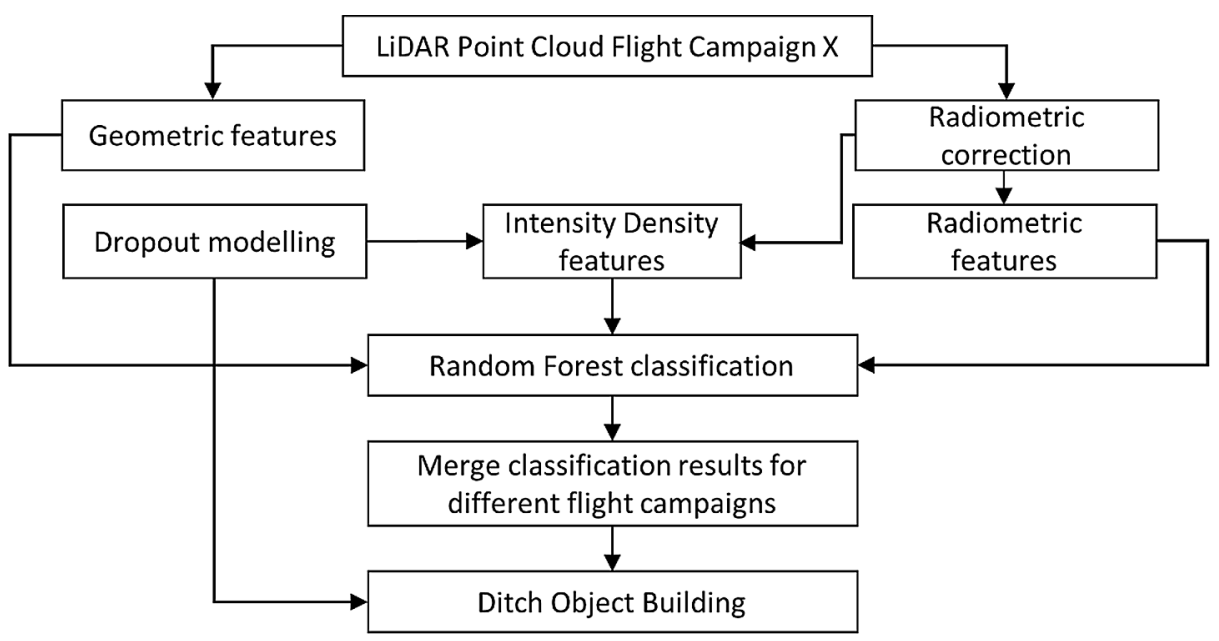

Fig. 2. Applied workflow for ditch mapping using LiDAR point clouds.

\subsection{Radiometric correction}

Calibrating, correcting or normalising the return strength of LiDAR points is not yet a standardised pre-processing step in LiDAR based projects (Malinowski et al., 2016). The return strength of a LiDAR point, also called the intensity $(\lambda=1550 \mathrm{~nm}, \mathrm{NIR})$ is also determined by the reflectance of the object hit by the laser pulse. Intensity values need to be corrected on an individual flight strip basis in order to increase the usability of the intensity information across flight strips (Ahokas et al., 2006; Boyd and Hill, 2007). As there is no full-waveform for the reflected LiDAR signals available through the data provider (AGIV, 2015b), the intensity values were corrected using the empirical model proposed by Ahokas et al. (2006):

$I_{\text {corrected }}=I_{\text {original }} \cdot \frac{R_{i}^{2}}{R_{\text {ref }}^{2}} \cdot \frac{E_{T r e f}}{E_{T j}}$

where $I_{\text {original }}$ is the original intensity value (DN, dimensionless), $R_{i}$ is the distance (range) from the sensor to the measuring point on the ground $(m), R_{r e f}$ is the chosen reference distance $(m), E_{T j}(J)$ is the pulse energy value in a current flight line and $\mathrm{E}_{\text {Tref }}(\mathrm{J})$ is the chosen reference pulse energy (Ahokas et al., 2006). As there were no different pulse energies used in the flight campaign, the pulse energy term $\left(\mathrm{E}_{\mathrm{Tref}} / \mathrm{E}_{\mathrm{Tj}}\right)$ was set to 1 .

To calculate the ranges $R_{i}$ between the point and the aircraft, the exact position $(\mathrm{X}, \mathrm{Y}, \mathrm{Z})$ of the aircraft had to be reconstructed for every scan line along the flight strip as the plane trajectory was not provided. The method is described and illustrated in Roelens et al. (2016). As can be assumed that on average there was no roll over the whole flight line and that the roll was equally distributed, the calculated positions of the plane can be compared to the general trend line of the flight. The mean error of the $\mathrm{X}$ and $\mathrm{Y}$ position of the aircraft along the general trend of the flight lines was $2.5 \mathrm{~m}$. This error results into a maximal difference of $1 \% 0$ for the calculated ranges.

\subsection{LiDAR dropout modelling}

Water surfaces lead to a high proportion of dropouts of measurements due to the absorption of the NIR laser beam (Höfle et al., 2009). The presence of dropouts or 'non-recorded' laser echoes complicate the interpretation of LiDAR point clouds but can be modelled by implementing a geometric method taking the maximum planimetric point distance between two points (MPPD) into account. For the used point cloud, the MPPD is $0.5 \mathrm{~m}$. Modelling the occurrence of dropouts was performed for each flight campaign separately. In the first step, a rasterized DEM with a cell size equal to the MPPD was created based on the LiDAR points. The centre points of the empty raster cells, i.e. in which no ground points were recorded, were then converted to points and labelled as preliminary dropouts. To make sure that these preliminary dropouts do not result from noise or occlusions, only preliminary dropouts that have eight adjacent empty raster cells were retained. Furthermore, to make sure that the remaining dropouts are due to the absorption by water, and are not points that had been classified as 'non-ground' points, the presence of 'non-ground' points on the location of the dropouts was taken into account. Dropouts that were at a distance of less than or equal to the MPPD to a 'non-ground' point were disregarded. The remaining points were then defined as actual dropouts. The intensity of the dropouts was set to zero, as proposed by Höfle et al. (2009), while the elevation (Z-value) of the dropouts was set equal to the elevation of the closest recorded LiDAR ground point.

\subsection{Feature extraction from the LiDAR point cloud}

Geometric, radiometric and intensity density features, as defined below, were extracted for each point in the LiDAR point cloud to separate ditch points from non-ditch points. All these features can be found in Tables 2-4. Dropouts were excluded for calculating the geometric and radiometric features, but were included for calculating the intensity density features.

\subsubsection{Geometric features}

The geometric features were all derived from the absolute elevation of the LiDAR points (m TAW, the official Belgian altimetric datum), with the Z-value of the LiDAR point being the only direct geometric feature. Common 3D geometric features that are used in 3D scene analysis are derived from the normalized eigenvalues $\left(e_{1}>e_{2}>e_{3}\right)$ within a local neighbourhood which encodes information about the spatial distribution of the LiDAR points. Eight local 3D shape features i.e. linearity $L_{\lambda}$, planarity $P_{\lambda}$, scattering $S_{\lambda}$, omnivariance $O_{\lambda}$, anisotropy $A_{\lambda}$, eigentropy $E_{\lambda}$, sum of eigenvalues $\Sigma_{\lambda}$ and change of curvature $\mathrm{C}_{\lambda}$ as defined by Weinmann (2016) were calculated:

$$
\begin{aligned}
& L_{\lambda}=\frac{e_{1}-e_{2}}{e_{1}} \\
& P_{\lambda}=\frac{e_{2}-e_{3}}{e_{1}} \\
& S_{\lambda}=\frac{e_{3}}{e_{1}} \\
& O_{\lambda}=\sqrt[3]{\prod_{i=1}^{3} e_{i}}
\end{aligned}
$$


Table 2

Radiometric and geometric features used for classification of LiDAR-points as (non-)ditch excluding dropouts.

\begin{tabular}{|c|c|c|c|}
\hline Feature type & Derived features & Reference & Search radii $(\mathrm{m})$ \\
\hline \multicolumn{4}{|l|}{ Direct features } \\
\hline Geometric features & Elevation & & Not Applicable (NA) \\
\hline \multirow[t]{5}{*}{ Radiometric features } & Intensity & Ahokas et al. (2006) & NA \\
\hline & $R, G, B$ & & NA \\
\hline & NDWI & McFeeters (1996) & NA \\
\hline & NDVI & Rouse et al. (1973) & NA \\
\hline & SSI & Chen et al. (2009) & NA \\
\hline \multicolumn{4}{|c|}{ Features derived in a local neighbourhood } \\
\hline \multirow[t]{12}{*}{ Geometric features } & Density & Mandlburger et al. (2009) & $0.5,1,1.5,2,3,4$ \\
\hline & Roughness & Höfle et al. (2009) & $0.5,1,1.5,2,3,4$ \\
\hline & Positive openness & Mandlburger et al. (2011) & $0.5,1,1.5,2,3,4$ \\
\hline & Negative openness & Mandlburger et al. (2011) & $0.5,1,1.5,2,3,4$ \\
\hline & Linearity & Weinmann (2016) & $0.5,1,1.5,2,3,4$ \\
\hline & Planarity & Weinmann (2016) & $0.5,1,1.5,2,3,4$ \\
\hline & Scattering & Weinmann (2016) & $0.5,1,1.5,2,3,4$ \\
\hline & Omnivariance & Weinmann (2016) & $0.5,1,1.5,2,3,4$ \\
\hline & Anisotropy & Weinmann (2016) & $0.5,1,1.5,2,3,4$ \\
\hline & Eigentropy & Weinmann (2016) & $0.5,1,1.5,2,3,4$ \\
\hline & Sum of eigenvalues & Weinmann (2016) & $0.5,1,1.5,2,3,4$ \\
\hline & Change of curvature & Weinmann (2016) & $0.5,1,1.5,2,3,4$ \\
\hline \multirow[t]{5}{*}{ Radiometric features } & $R, G, B$ variance & & $0.5,1,1.5,2,3,4$ \\
\hline & NDWI variance & & $0.5,1,1.5,2,3,4$ \\
\hline & NDVI variance & & $0.5,1,1.5,2,3,4$ \\
\hline & SSI variance & & $0.5,1,1.5,2,3,4$ \\
\hline & Intensity variance & Höfle et al. (2009) & $0.5,1,1.5,2,3,4$ \\
\hline
\end{tabular}

Table 3

Used intensity upper thresholds for each flight campaign for calculating the intensity density.

\begin{tabular}{lll}
\hline & Flight campaign date & Intensity thresholds (DN) \\
\hline \multirow{2}{*}{ SA1 } & $02 / 03 / 2014$ & 20,40 \\
& $30 / 03 / 2014$ & 30,50 \\
SA2 & $03 / 11 / 2015$ & 150,250 \\
\hline
\end{tabular}

Table 4

Intensity density features of points used for classification as (non-)ditch with (SA1) and without (SA2) dropouts.

\begin{tabular}{lllll}
\hline Derived features & $\begin{array}{l}\text { Search } \\
\text { radii }(\mathrm{m})\end{array}$ & $\begin{array}{l}\text { Linear } \\
\text { search radii } \\
(\mathrm{m})\end{array}$ & $\begin{array}{l}\text { Upper } \\
\text { threshold } \\
\text { Intensity }\end{array}$ & $\begin{array}{l}\text { Min. intensity } \\
\text { density (DN) }\end{array}$ \\
\hline $\begin{array}{l}\text { Intensity density } \\
\text { Linear intensity } \\
\text { density }\end{array}$ & $0.5,1,2,4$ & - & Table 3 & \\
$+\mathrm{R}^{2}$ & $0.5,1,2,4$ & 5,15 & Table 3 & $30,50,70$ \\
+ Line direction & & & & \\
\hline
\end{tabular}

$A_{\lambda}=\frac{e_{1}-e_{3}}{e_{1}}$

$E_{\lambda}=-\sum_{i=1}^{3} e_{i} \ln \left(e_{i}\right)$

$\Sigma_{\lambda}=\sum_{i=1}^{3} e_{i}$

$C_{\lambda}=\frac{e_{3}}{\sum_{i=1}^{3} e_{1}}$

Other features calculated in a local neighbourhood were the point density, roughness, and positive and negative openness. The point density is defined as the ratio of the point count within the neighbourhood and the area of the neighbourhood (Mandlburger et al., 2009). Roughness (m) is defined as the standard deviation of the height values with respect to a locally fitted plane (Höfle et al., 2009).
Openness is defined as an angular measure denoting the aperture angle of a cone centred at the LiDAR point and constrained by the neighbouring elevations in the local neighbourhood (Mandlburger et al., 2011; Yokoyama et al., 2002). For calculating the positive and negative openness, the mean value of all zenith angles and respectively nadir angles were used (Doneus, 2013). The eight local 3D shape features, the point density, roughness and positive and negative openness were calculated for local neighbourhoods with radii equalling 1, 2, 3, 4, 6 and 8 times the MPPD in the LiDAR point cloud, which correspond to $0.5,1$, $1.5,2,3$ and $4 \mathrm{~m}$ (Table 2).

\subsubsection{Radiometric features}

The direct radiometric features consisted of the red, green and blue band values, and the corrected intensity value used as a proxy for NIRreflectance (Roelens et al., 2016). Based on these features, the Normalized Difference Water Index (NDWI) (McFeeters, 1996), Normalized Difference Vegetation Index (NDVI) (Rouse et al., 1973) and Spectral Shape Index (SSI) (Chen et al., 2009) were calculated:

$N D W I=\frac{\text { Green }-N I R}{\text { Green }+ \text { NIR }}$

$N D V I=\frac{N I R-R e d}{N I R+R e d}$

$S S I=\operatorname{abs}($ Red + Blue $-2 *$ Green $)$

For all of these direct radiometric features, R, G, B, intensity, NDWI, NDVI and SSI, the variance was calculated in local neighbourhoods with radii equalling those used for the geometric features (Table 2).

\subsubsection{Intensity density features}

Features derived from the corrected intensity values (Section 3.1) consisted of the 'intensity density' and the 'linear intensity density'. The term 'intensity density' (\%) was introduced by Clode et al. (2005) and further defined by Höfle et al. (2009) and is the percentage of neighbours with an intensity below a threshold. The threshold was determined using training data, which were three cross-sections per flight campaign with known positions from the ground truth data (Table 3). The intensity density was calculated using the same neighbourhoods as those used for the geometric and radiometric features (Table 4). 
It is assumed that LiDAR points that occur in ditches will have a high intensity density as low intensities coincide with water surfaces and saturated soils. As high intensity densities could also occur outside ditches, the 'linear intensity density' feature was developed. LiDAR points with high intensity densities that are located in ditches should have a very good linear fit. This is addressed by calculating the linearity of the spatial distribution of points that fulfil a high intensity density. The linear intensity density was thus only calculated for and with LiDAR points with a minimum value for intensity density (Table 3 ). The linearity of these points was computed by using a robust line fitting within the random sample consensus (RANSAC) framework (Fischler and Bolles, 1981). The linear intensity density (\%) is then defined as the percentage of points used for line fitting (RANSAC inliers) vs. all the points in a neighbourhood with a radius defined as the 'linear search radius' (Table 4). For the derived linear inlier model, the coefficient of determination (R2) and line direction were also calculated (Table 4).

Given the preliminary classification results for SA1 and the dropout modelling results for SA2, the modelled dropouts were not used for the intensity density calculation of SA2 as these were not modelled with a high accuracy. In addition, the linear intensity density with its $\mathrm{R}^{2}$ and line direction were not calculated for SA2.

\subsection{LiDAR-point classification}

The supervised machine learning classifier Random Forest (RF) was used for classifying the LiDAR points in a ditch and non-ditch class. Different feature subsets were considered (Table 5). A RF classifier was chosen as it was reported to return good classification results for LiDAR points while it also allows for feature selection (Chehata et al., 2009; Koenig et al., 2015). A RF classifier consists of a collection of treestructured classifiers where the set of predictor variables is randomly restricted at each split (Breiman, 2001). This reduces the correlation between the individual trees with the aim of improving the overall predictive power and efficiency (Miao et al., 2012). RF perform an implicit feature selection using the Gini index to measure how well a potential split is separating the samples of the two classes in a particular node. The outcome of this implicit feature selection can be visualized using the Gini importance metric (Breiman, 2001; Menze et al., 2009).

Balanced RF with 1000 trees, which handle the unbalance in the training data between the number of ditch and non-ditch points, were modelled using the machine learning scikit-learn package of Python (Pedregosa et al., 2011). The training data for each classification consisted of a random subsample of the LiDAR points, that were assigned a reference ditch class (Section 2.3), with a number equal to $0.5 \%$ of the total number of points in the point cloud or at least 2000 points (Table 1). The trained RF-classifier was then applied to the remaining LiDAR points to obtain a class prediction for each point.

\section{Table 5}

Feature subsets and its number of features (considering the different neighbourhoods) representing different combinations of the radiometric, geometric and intensity density features for the classification of LiDAR points.

\begin{tabular}{llll}
\hline \multirow{2}{*}{$\begin{array}{l}\text { Subset } \\
\text { name }\end{array}$} & Feature type & \multicolumn{2}{l}{ No. features } \\
\cline { 3 - 4 } & & SA1 & SA2 \\
\hline Subset 1 & Geometric features & 73 & 73 \\
Subset 2 & Radiometric features & 49 & 49 \\
Subset 3 & Intensity density features & 50 & 10 \\
Subset 4 & Geometric features + radiometric features & 122 & 122 \\
Subset 5 & Radiometric features + Intensity density features & 99 & 59 \\
Subset 6 & Geometric features + Intensity density features & 123 & 83 \\
Subset 7 & Geometric features + radiometric & 172 & 132 \\
& features + Intensity density features & & \\
\hline
\end{tabular}

\subsection{Ditch object building}

For each of the subsets in Table 5, points classified by the RF classifier as 'ditch' were merged for each study area to create a ditch point density map with a cell size equal to the MPPD $(=0.5 \mathrm{~m})$. This was done to remove outlying ditch points as the denser the ditch points are, the higher the probability these are true ditch points. The point density map was thresholded using one standard deviation of the density favouring the cells with a higher density. Ditch points located within these cells were then selected and aggregated in polygons using alpha shapes with a maximum distance between the points equalling the largest search radius used $(=4 \mathrm{~m})$.

To remove from the created polygons the isolated non-linear ones, the shape index was computed for each polygon according to Forman and Godron (1986):

Shapeindex $=\frac{\text { Perimeter }}{2 * \sqrt{\text { Area } * \pi}}$

The shape index measures the complexity of a patch independently of its size. The shape index equals to 1 for circles, 1.13 for squares and 1.20 for rectangles with a length to width ratio of 2:1 (Forman and Godron, 1986). The shape index was then thresholded using one standard deviation with a minimum of 1.20 to select the polygons with the most linear shape. The resulting polygons were then considered as the final ditch polygons. To obtain the centre line of a ditch polygon, the polygon was skeletonized based on the Conformal Delaunay Triangulation with a resolution of $0.5 \mathrm{~m}$ (Chithambaram et al., 1991). The skeleton was trimmed by removing dangling lines shorter than $5 \mathrm{~m}$. As the dropouts, that were the result of the absorption of the laser signal due to water, were modelled as potential ditch points, their effect on the resulting ditch objects was evaluated by adding them to the selected ditch points for the aggregation step and repeating the rest of the ditch object building procedure.

\subsection{Validation}

The classification of the LiDAR points was evaluated by the overall accuracy, the correctness (user's accuracy $=1$ - error of commission) and completeness (producer's accuracy $=1-$ error of omission) for the ditch class (Heipke et al., 1997), and the Kappa coefficient as derived from the confusion matrix. The validity of the extracted centre lines was tested by uniformly discretising these with an inter-vertex distance equal to the MPPD $(0.5 \mathrm{~m})$. For each vertex the shortest Euclidean distance to the ditch centre lines in the reference dataset was determined. The positional accuracy was then calculated as the mean absolute difference of these Euclidian distances under a threshold of $2 \mathrm{~m}$. Points at a distance larger than this threshold, were considered as errors of commission. Also the opposite was done, i.e. the reference centre lines were also discretised and the shortest Euclidian distances were calculated to the extracted centre lines. Points at a distance larger than the threshold of $2 \mathrm{~m}$ were considered as errors of omission (Broersen et al., 2017; Roelens et al., 2018).

\section{Results}

\subsection{Dropout modelling}

The number of modelled dropouts, its ratio to the number of ground points and the fraction that was inside the reference ditch polygons are presented in Table 6 for each of the three flight campaigns. For the two flight campaigns in SA1, 95\% and $91 \%$ of the modelled dropouts were located inside the reference ditch polygons. Visualizing the modelled dropouts for SA1 revealed that the dropouts that were not located in the reference ditch polygons were located in the south-western part of the study area (Fig. 3). Field observations indicated that this location corresponded to standing water in a presumably old and no longer 
Table 6

Total number of modelled dropouts, its ratio to the number of ground points and fraction of dropouts modelled within the reference ditch polygons per flight campaign.

\begin{tabular}{lllll}
\hline Study area & $\begin{array}{l}\text { Flight } \\
\text { campaign } \\
\text { date }\end{array}$ & No. dropouts & $\begin{array}{l}\text { Ratio of } \\
\text { dropouts to } \\
\text { ground points } \\
(\%)\end{array}$ & $\begin{array}{l}\text { Fraction of } \\
\text { dropouts within } \\
\text { ditch class }\end{array}$ \\
\hline SA1 & $02 / 03 / 2014$ & 2450 & 0.17 & 0.95 \\
& $30 / 03 / 2014$ & 1881 & 0.82 & 0.91 \\
SA2 & $03 / 11 / 2015$ & 4126 & 0.01 & 0.00 \\
\hline
\end{tabular}

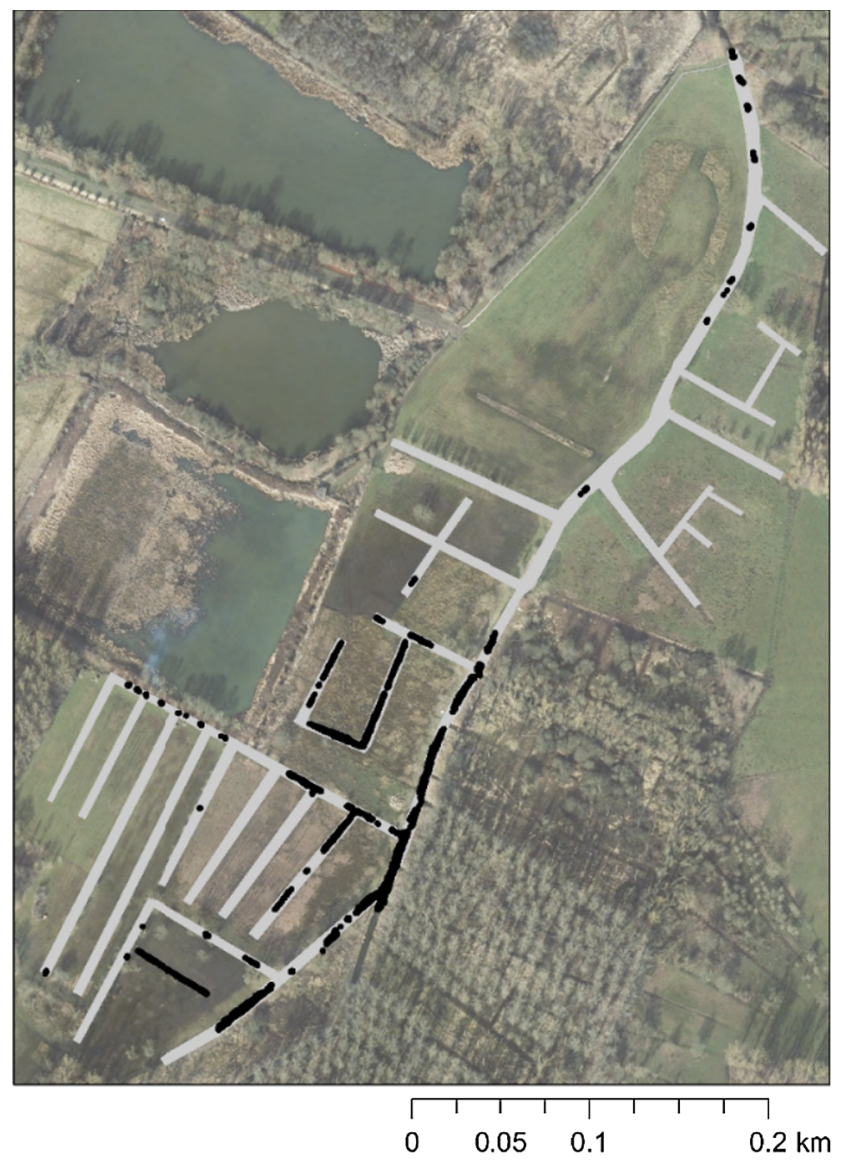

Fig. 3. Location of the dropouts (black dots) in study area 1 . The grey polygons show the reference ditch polygons.

maintained ditch. For SA2, almost no dropouts were modelled in comparison to SA1. In addition, none of the dropouts were located in the reference ditch polygons. Visualizing the modelled dropouts for SA2 on the RGB images revealed that these were mainly located in garden ponds and in puddles of standing water on agricultural fields.

\subsection{Classification of the LiDAR points}

The results of the RF classification considering different feature subsets are presented in Table 7 . When using all the available features for point classification, the Kappa coefficient revealed a good level of agreement (0.77 for SA1 and 0.73 for SA2, Altman, 1990). For both study areas, almost all the subsets generated a high ditch class correctness ( $>0.75$ ). However, correctness was degraded due to edge effects that occurred as the local neighbourhood of points located near the edge of the study area did not allow retrieving all the information needed for fair extraction of the features (Fig. 4). Furthermore, the correctness with which the ditch points could be detected was higher in SA1 than in SA2.

With high ditch class correctness, the completeness was decisive for judging the quality of the classification. For both study areas, ditch completeness was the highest for subsets $1,4,6$ and 7 which all encompass the geometric features. For SA1, adding first the radiometric features and next the intensity density features slightly improved the completeness of the ditch classification results (Table 7). For the periurban study area (SA2), there is no difference in the completeness and Kappa values for these subsets, which translates to no added value of the radiometric and intensity density features for SA2.

The LiDAR points for SA1 classified using the geometric, radiometric or intensity density features (subset 1,2 or 3 ) are visualized in Fig. 4(a)-(c). Using the geometric features for ditch detection resulted in the best ditch classification correctness. However, in addition to errors related to edge effects, still some errors of commission occurred where isolated individual trees were present (Fig. 4(a)). In these locations, a change of curvature or roughness occurred due to a poor distinction between the 'ground' points and the stem of the trees. Errors of omission occurred in zones where ditches had dense vegetation, or appeared very shallow due to high water levels.

Classification using radiometric features could also correctly identify ditch points, but the ditch detection completeness was low (Table 7). Apart from the edge effects, errors of commission were here more spread across the study area and could be linked to the heterogeneity of vegetation and vegetation overhanging the ditch. Errors of omission occurred at the upper end of ditches where there was less water or where there was dense vegetation.

Using the intensity density features yielded the poorest classification results. Ditch detection completeness values were 0.30 for SA1 and 0.09 for SA2 (Table 7). The reason that these values are three times as high for SA1 than for SA2 is that dropouts, that were assigned an intensity of zero, were included for extracting the intensity density features for SA1. As intensity density features are dependent on the intensity values of the LiDAR points, errors of omission occurred in dry ditches with lower soil moisture and thus higher intensity values. Many errors of commission occurred and were spread throughout the whole study area. The errors of commission that occurred here were also present in the classification results using the radiometric features (Fig. 4(b)-(c)).

The Gini importance values for the 10 most important features building the RF classifier from all the available features (subset 7) are shown for SA1 (flight campaign 02/03/2014) in Fig. 5(a) and for SA2 in Fig. 5(b). For SA2, the 10 most important features are all geometric features, which is consistent with the findings in Table 7. For SA1, next to 8 geometric features, only the variance of the radiometric features NDWI and NDVI in a local neighbourhood of $2 \mathrm{~m}$ were listed. For the geometric features used in SA1, the local radii of $3 \mathrm{~m}$ and $4 \mathrm{~m}$ were most frequently selected. For SA2, this was $2 \mathrm{~m}$ for the five most important geometric features. Although the rank differed, the most important features for ditch classification in both the study areas were roughness (variance in elevation) and change of curvature. They appeared more than once with different neighbourhoods in the 10 most important features for classification. The geometric features omnivariance, scattering and anisotropy were also selected for both study areas. For SA1, the absolute elevation of the LiDAR point also plays a role.

\subsection{Ditch object building}

Two examples for the 2D ditch polygon objects derived from the classified points for both the study areas are displayed in the insets of Fig. 1. The errors of omission and commission and the positional accuracy of the centre lines derived from these ditch polygons for both the study areas are shown in Table 8. For SA2, the errors of commission were about equal for all the subsets (0.07), but the lowest errors of omission (0.14) were obtained for subsets 1 and 6 both containing the 
Table 7

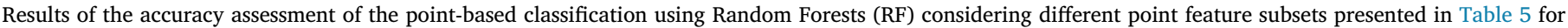
both study areas ( $\mathrm{G}=$ Geometric, $\mathrm{R}=$ Radiometric, ID = Intensity Density).

\begin{tabular}{|c|c|c|c|c|c|c|c|c|}
\hline & \multirow[t]{2}{*}{ Subset } & \multicolumn{3}{|c|}{ Feature subsets } & \multirow[t]{2}{*}{ Overall accuracy } & \multicolumn{2}{|l|}{ Ditch class } & \multirow[t]{2}{*}{ Kappa } \\
\hline & & G & $\mathrm{R}$ & ID & & Correctness & Completeness & \\
\hline \multirow[t]{7}{*}{ SA1 } & Subset 1 & $x$ & & & 0.96 & 0.87 & 0.67 & 0.73 \\
\hline & Subset 2 & & $x$ & & 0.94 & 0.83 & 0.46 & 0.56 \\
\hline & Subset 3 & & & $\times$ & 0.91 & 0.67 & 0.30 & 0.38 \\
\hline & Subset 4 & $x$ & $\times$ & & 0.96 & 0.89 & 0.69 & 0.76 \\
\hline & Subset 5 & & $x$ & $x$ & 0.94 & 0.85 & 0.44 & 0.55 \\
\hline & Subset 6 & $x$ & & $x$ & 0.96 & 0.88 & 0.65 & 0.72 \\
\hline & Subset 7 & $x$ & $x$ & $x$ & 0.96 & 0.88 & 0.71 & 0.77 \\
\hline \multirow[t]{7}{*}{ SA2 } & Subset 1 & $x$ & & & 0.99 & 0.81 & 0.67 & 0.73 \\
\hline & Subset 2 & & $\times$ & & 0.98 & 0.77 & 0.23 & 0.35 \\
\hline & Subset 3 & & & $\times$ & 0.98 & 0.76 & 0.09 & 0.16 \\
\hline & Subset 4 & $x$ & $\times$ & & 0.99 & 0.82 & 0.67 & 0.73 \\
\hline & Subset 5 & & $x$ & $x$ & 0.98 & 0.79 & 0.24 & 0.36 \\
\hline & Subset 6 & $x$ & & $x$ & 0.99 & 0.81 & 0.67 & 0.73 \\
\hline & Subset 7 & $x$ & $x$ & $x$ & 0.99 & 0.82 & 0.67 & 0.73 \\
\hline
\end{tabular}

geometric features. For SA1 the lowest errors occurred for subsets containing the geometric and radiometric features with an error of omission of 0.05 and an error of commission of 0.08. Adding the modelled dropouts reduced the error of omission to 0.03 , but slightly increased the error of commission to 0.09 (Table 9) due to the wrongly modelled dropouts in Fig. 3. The derived ditch centre lines for the subsets with the lowest errors had furthermore a high positional accuracy $(<0.5 \mathrm{~m})$.

\section{Discussion}

\subsection{Dropout modelling}

Dropouts were modelled assuming that they are 'lost' LiDAR points due to absorption by water in ditches (Höfle et al., 2009). For the separate flight campaigns over the grassland area (SA1), dropouts were modelled with a high correctness. Taking into account the non-ground points - to make sure that the dropouts were only the result from water absorption - had the desired effect, but also led to the removal of correctly modelled dropouts when there was vegetation overhanging the ditch, which was more the case for SA2 than for SA1. For areas with a more heterogeneous land use, such as SA2, the method for dropout modelling should be improved by taking into account overhanging vegetation and nearby anthropogenic structures. The dropout modelling method developed in this research is based on the geometric properties of the flight strips and only information on the maximum planimetric point distance between two points (MPPD) is needed. This is a good solution when not all information about the retrieval of the LiDAR data is available, such as the aircraft location and attitude in this study. However, information may be lost when ignoring the scanning geometry. This could be solved by reorienting the raster used for DEM interpolation in Section 3.2 in the direction of the reconstructed scan lines. Preferably, complete data on the LiDAR acquisition campaigns should be available, making it possible to compare the validity of the used dropout modelling method to the one of Höfle et al. (2009) where the timestamp, aircraft location and attitude are directly taken into account.

\subsection{LiDAR point classification}

Geometric, radiometric and derived intensity features were extracted for each LiDAR point and used to classify them as ditch or nonditch using a Random Forest classifier. The classifiers were trained and evaluated using the reference ditch class of the LiDAR points that were identified using the ditch polygons measured in the field for SA1 and the ditch polygons created using modelled cross-sections in SA2. The absolute mean error on the extracted width of the cross-section was $0.15 \mathrm{~m}$. This error could have some limited impact as LiDAR points
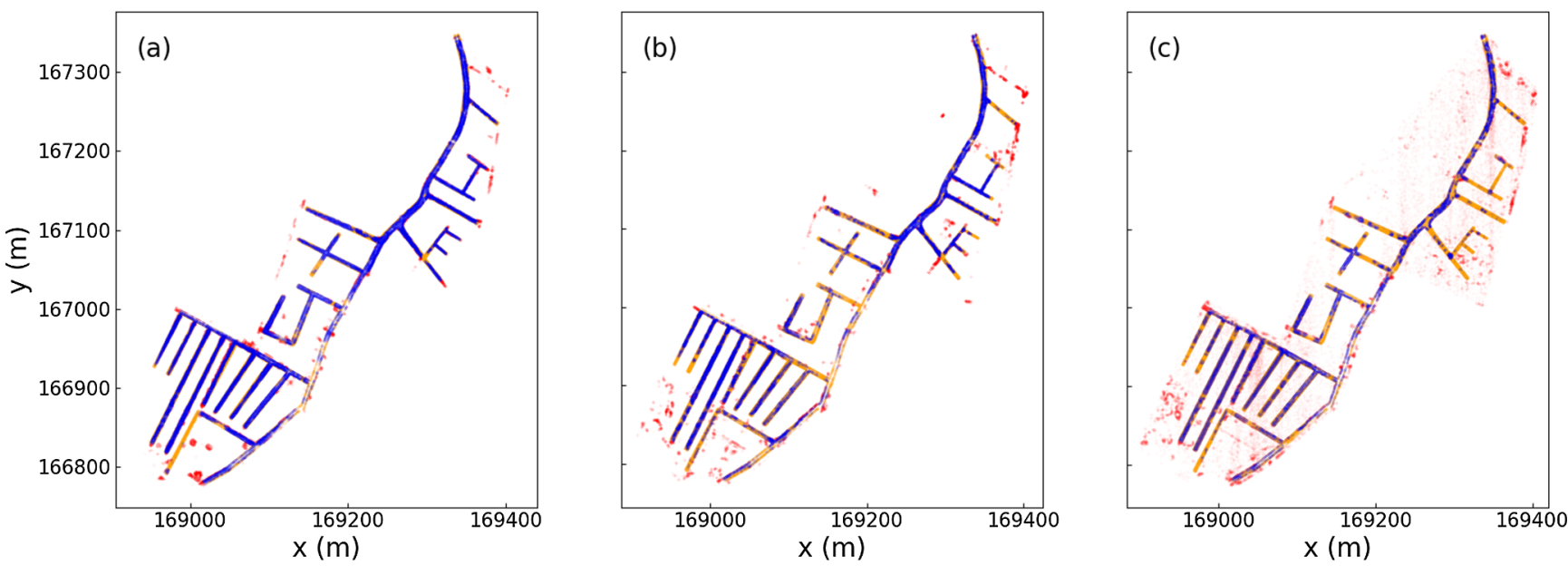

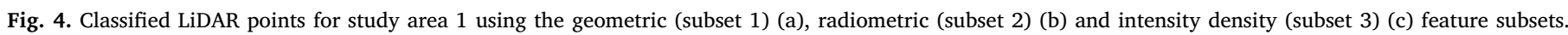

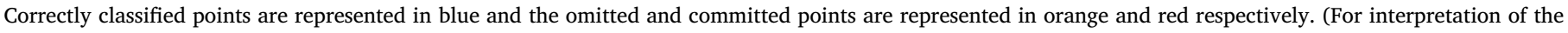
references to color in this figure legend, the reader is referred to the web version of this article.) 

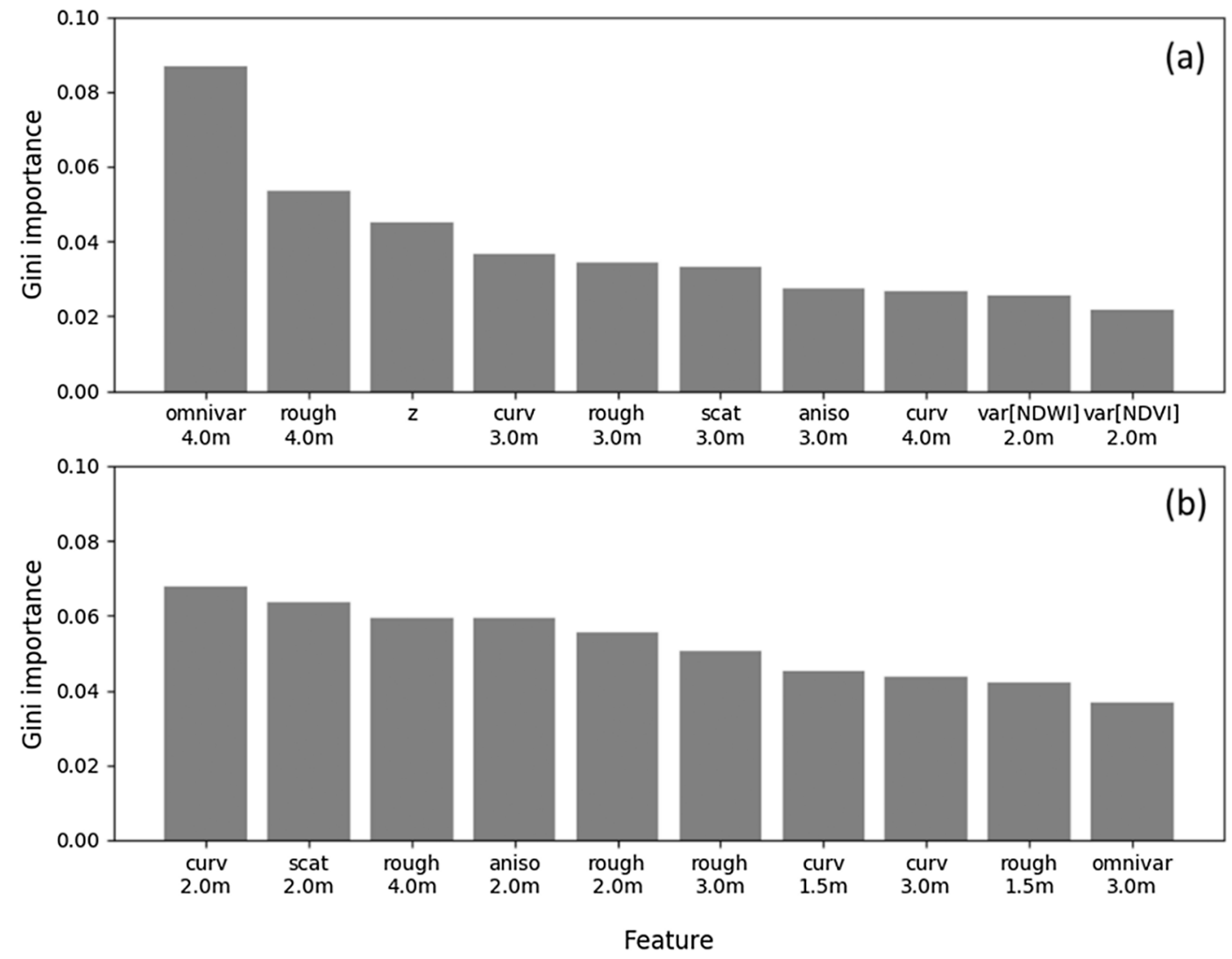

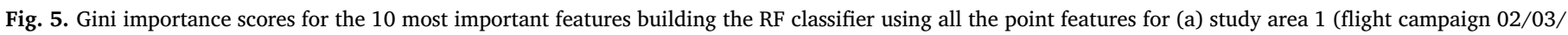
2014) and (b) study area 2 (omnivar $=$ omnivariance, rough $=$ roughness, curv $=$ change in curvature, scat $=$ scattering, aniso $=$ anisotropy, var $=$ variance).

Table 8

Validity of the extracted centre lines considering different feature subsets for the classification of the underlying LiDAR-points in both study areas.

\begin{tabular}{llllllll}
\hline & Subset & \multicolumn{2}{l}{ Feature subsets } & $\begin{array}{l}\text { Error of } \\
\text { omission }\end{array}$ & $\begin{array}{l}\text { Error of } \\
\text { commission }\end{array}$ & $\begin{array}{l}\text { Positional } \\
\text { accuracy (m) }\end{array}$ \\
\cline { 3 - 5 } & & $\mathrm{G}$ & $\mathrm{R}$ & $\mathrm{ID}$ & & & \\
\hline SA1 & Subset 1 & $\times$ & & & 0.09 & 0.12 & 0.47 \\
& Subset 2 & & $\times$ & & 0.14 & 0.20 & 0.53 \\
& Subset 3 & & & $\times$ & 0.23 & 0.42 & 0.75 \\
& Subset 4 & $\times$ & $\times$ & & $\mathbf{0 . 0 5}$ & $\mathbf{0 . 0 8}$ & 0.47 \\
Subset 5 & & $\times$ & $\times$ & 0.18 & 0.18 & 0.56 \\
& Subset 6 & $\times$ & & $\times$ & 0.07 & $\mathbf{0 . 0 8}$ & 0.44 \\
& Subset 7 & $\times$ & $\times$ & $\times$ & 0.07 & 0.09 & 0.46 \\
SA2 & Subset 1 & $\times$ & & & $\mathbf{0 . 1 4}$ & $\mathbf{0 . 0 7}$ & 0.48 \\
Subset 2 & & $\times$ & & 0.68 & 0.08 & 0.43 \\
Subset 3 & & & $\times$ & 0.87 & 0.08 & 0.46 \\
Subset 4 & $\times$ & $\times$ & & 0.15 & $\mathbf{0 . 0 7}$ & 0.48 \\
Subset 5 & & $\times$ & $\times$ & 0.68 & 0.08 & 0.43 \\
Subset 6 & $\times$ & & $\times$ & $\mathbf{0 . 1 4}$ & $\mathbf{0 . 0 7}$ & 0.48 \\
Subset 7 & $\times$ & $\times$ & $\times$ & 0.15 & $\mathbf{0 . 0 7}$ & 0.48 \\
\hline
\end{tabular}

close to the border of the reference ditch polygon could be misclassified as ditch or non-ditch in the reference LiDAR point dataset used for the training of the classification and for assessment of validity.

Using all the available features for point classification resulted in Kappa coefficients representing good levels of agreement with the reference data (Altman, 1990). For both study areas, all the subsets generated an equally high ditch class correctness, making the completeness decisive for the quality of the classification. In general, the geometric features had the greatest influence on the classification quality. In contrast to the grassland area, the radiometric features variance of NDWI and NDVI - had no added value on the classification results for the peri-urban study area. This is because RGB measurements are passive measurements that can only be used in a correct way in combination with a single return of the LiDAR pulse. LiDAR points that were classified in the LiDAR product as 'ground', and used for the classification, mostly include either single or last returns. For LiDAR pulses that only contain a single return, the intensity and RGB values are combined in a correct way, which is not the case for last returns. In this case, the RGB values will probably be characteristic for one of the first returns. For the peri-urban study area, there was a smaller fraction of single returns resulting in no added value of the NDWI and NDVI. However, to get the most out of ditch detection results, radiometric features should also be taken into account as they can have a positive effect on the quality of the classification which is the case for both SA1 and SA2. The errors that occurred when only using the intensity density features were significantly higher than the errors occurring in the other classification results. However, the intensity density features were able to cancel out the wrongly identified dropouts due to the higher intensity values of the LiDAR points surrounding these dropouts.

Remaining errors in the classification can be summarized in three categories: edge effects, accidental poor distinctions between ground and non-ground points in the LiDAR-product, and vegetation effects. The edge effects could be avoided by buffering the study area for feature extraction. Further errors could be reduced firstly by using an improved, more recent and detailed LiDAR point classification method to differentiate between ground and non-ground points (Chen et al., 2017); and lastly - as already discussed - by improving the method for dropout modelling by taking into account overhanging vegetation. Overhanging vegetation as a limitation for ditch detection methods using LiDAR point clouds was also recognized by Broersen et al. (2017) and could thus not be solved completely by adding more properties (such as intensity) derived from the LiDAR product. Using LiDAR systems with smaller footprints and higher laser pulse repetition rate or bathymetric LiDAR systems (for water penetration) could also help 
Table 9

Validity of the extracted centre lines considering different feature subsets for the classification of the underlying LiDAR-points in study area 1, incorporating the modelled dropouts.

\begin{tabular}{llllllll}
\hline \multirow{2}{*}{ Subset } & \multicolumn{2}{l}{ Feature subsets } & & $\begin{array}{l}\text { Error of } \\
\text { omission }\end{array}$ & $\begin{array}{l}\text { Error of } \\
\text { commission }\end{array}$ & $\begin{array}{l}\text { Positional } \\
\text { accuracy (m) }\end{array}$ \\
\cline { 3 - 5 } & & G & R & ID & & & \\
\hline \multirow{2}{*}{ SA1 } & Subset 1 & $\times$ & & & 0.06 & 0.12 & 0.47 \\
& Subset 2 & & $\times$ & & 0.09 & 0.18 & 0.53 \\
& Subset 3 & & & $\times$ & 0.20 & 0.40 & 0.74 \\
& Subset 4 & $\times$ & $\times$ & & 0.04 & $\mathbf{0 . 0 9}$ & 0.48 \\
Subset 5 & & $\times$ & $\times$ & 0.13 & 0.14 & 0.55 \\
Subset 6 & $\times$ & & $\times$ & 0.06 & 0.10 & 0.44 \\
Subset 7 & $\times$ & $\times$ & $\times$ & $\mathbf{0 . 0 3}$ & $\mathbf{0 . 0 9}$ & 0.47 \\
\hline
\end{tabular}

overcome some of the above mentioned errors. Furthermore, processing full waveform LiDAR data could give more features to take into account for classification.

The Gini importance allowed to gain knowledge about the individual features most influencing the quality of the classification. Fig. 5 makes clear that the RF classifiers are not completely spatially transferrable. This is especially true for the z-coordinate as the elevation (z-coordinate) in the first study area only differs $1.5 \mathrm{~m}$ and is an important feature for classification, while in the second study area the elevation differs $9.6 \mathrm{~m}$ and the standard deviation in the z-coordinate (roughness) becomes a more interesting variable than the z-coordinate. Roughness and change of curvature are the most important geometric features for classification in both the study areas. These two geometric features are most able to distinguish ditches from other landscape elements and are important in heterogeneous areas, such as the second study area. The relevance of these features is demonstrated in other ditch detection methods using the curvature in point clouds (Bailly et al., 2008; Broersen et al., 2017) or ditch detection methods using raster DEMs where curvature (Passalacqua et al., 2012) or the relative elevation attribute (REA) is used as indicator for roughness (Cazorzi et al., 2013; Roelens et al., 2018). For SA2, ditch networks were derived in previous research based on the REA with errors of omission and commission between 0.05 and 0.17 (Roelens et al., 2018).

As curvature and roughness for different neighbourhood sizes appear among the most important features, calculating these geometric features using different neighbourhood sizes/kernel sizes is recommended. Also, omnivariance, scattering, anisotropy, variance of NDWI and variance of NDVI played a role in the quality of classification. The acquired LiDAR data for Flanders contained at least 16 points per square meter leading to computationally and data intensive processing of the LiDAR data even for smaller areas and neighbourhoods (Wang et al., 2017). To reduce this processing time, rasterized DEMs could be evaluated for ditch detection using other geometric features than curvature and roughness, or combining these with intensity and NDWI and NDVI values.

\subsection{Ditch object building}

As the ditch objects were derived from the cloud of classified points, the errors for the obtained objects using the different feature subsets are in line with the previously mentioned reasons for imperfect point classification. Errors of commission in the point classification that corresponded to isolated points were reduced by only aggregating points that were in areas of high point densities. Furthermore, errors of commission that corresponded to (circular) point clusters could be reduced by only keeping ditch polygons with a high shape index value. Errors of omission were reduced by filling the holes in the ditch polygons by adding the modelled dropouts. As for SA2, this was not possible, remaining irregularities in the shape of the ditch polygons could be improved by using a 'buffer-debuffer operation', also called 'blow and shrink' (Broersen et al., 2017). Remaining errors of commission in the derived ditch objects are mostly weakly expressed linear features in the landscape. These should not always been seen as 'errors' and interpretation could benefit from expert knowledge. These are possibly relicts in the landscape that could for example be of archaeologic interest.

\section{Conclusion}

We proposed and evaluated a workflow to classify LiDAR points as ditch and non-ditch points and to assemble the ditch points into ditch objects (2D-polygons) whereby a new method for LiDAR dropout modelling was developed. Geometric features had the greatest influence on the accuracy of the classification of ditches, and adding radiometric features to the geometric features improved the results for the grassland study area. For the peri-urban study area, which was more heterogeneous and had more anthropogenic elements, radiometric features had no added value for the classification. This can be due to the RGB values that could not be combined with the corrected intensities as these correspond only with single or the one of the first returns of LiDAR points. Using intensity density features had no added value for any of the study areas. The most important features for classification were the change of curvature and roughness of LiDAR points in local neighbourhoods with radii between $2 \mathrm{~m}$ and $4 \mathrm{~m}$. Multi-scaling these geometric features by using different neighbourhoods facilitates the determination of ditch objects and can also be tested in rasterized DEMs to reduce the calculation time. Using other geometric features than curvature and roughness, or the combination of these with NDWI and NDVI can also be used for evaluating detecting ditches based on rasterized DEMs. Our method can be used for completing hydrographic inventories with smaller unmapped entities and, with future LiDAR campaigns, keeping such datasets up-to-date. Furthermore, availability of accurate ditch centre lines and ditch boundaries will facilitate the determination of geometric ditch characteristics such as width, crosssectional shape and area and water level. Furthermore, the workflow developed in this research can be adapted and applied to extract different features in the landscape.

\section{Acknowledgments}

This research was funded by the Department of Earth and Environmental Sciences of the University of Leuven (KU Leuven). The LiDAR data was made available by the Flemish Information Agency (AIV) (former AGIV). We thank the NGO 'Vrienden van Heverleebos en Meerdaalwoud' (VHM) for authorizing us to work in the nature reserve 'de Doode Bemde' (SA1).

\section{References}

Agentschap Onroerend Erfgoed, 2013. Vijvergebied tussen Laambeek en Slangebeek [WWW Document]. Inventar. Onroer. Erfgoed.

AGIV, 2015a. Orthofotomozaïek, kleinschalig, zomeropnamen, kleur, 1979-1990, Vlaanderen.

AGIV, 2015b. LiDAR Digitaal Hoogtemodel Vlaanderen II - ruwe remote sensing data.

Ahokas, E., Kaasalainen, S., Hyyppä, J., Suomalainen, J., 2006. Calibration of the Optech ALTM 3100 laser scanner intensity data using brightness targets. Int. Arch. Photogramm. Remote Sens. Spat. Inf Sci. 36.

Altman, D.G., 1990. Practical Statistics for Medical Research. CRC Press.

Andersson, J.C.M., Pechlivanidis, I.G., Gustafsson, D., Donnelly, C., Arheimer, B., 2015. Key factors for improving large-scale hydrological model performance. Eur. Water 49, 77-88.

Bailly, J.S., Lagacherie, P., Millier, C., Puech, C., Kosuth, P., 2008. Agrarian landscapes linear features detection from LiDAR: application to artificial drainage networks. Int. J. Remote Sens. 29, 3489-3508. https://doi.org/10.1080/01431160701469057.

Boyd, D.S., Hill, R.A., 2007. Validation of airborne lidar intensity values from a forested landscape using HYMAP data: preliminary analyses. Int. Arch. Photogramm. Remote Sens. 36, 71-76.

Breiman, L., 2001. Random forests. Mach. Learn. 45, 5-32. https://doi.org/10.1023/ A:1010933404324.

Broersen, T., Peters, R., Ledoux, H., 2017. Automatic identification of watercourses in flat and engineered landscapes by computing the skeleton of a LiDAR point cloud. 
Comput. Geosci. 106, 171-180. https://doi.org/10.1016/j.cageo.2017.06.003.

Brzank, A., Heipke, C., 2006. Classification of Lidar Data into water and land points in coastal areas. Int. Arch. Photogramm. Remote Sens. Spat. Inf. Sci. 36, 197-202.

Buchanan, B., Easton, Z.M., Schneider, R.L., Walter, M.T., 2013. Modeling the hydrologic effects of roadside ditch networks on receiving waters. J. Hydrol. 486, 293-305. https://doi.org/10.1016/j.jhydrol.2013.01.040.

Carluer, N., De Marsily, G., 2004. Assessment and modelling of the influence of manmade networks on the hydrology of a small watershed: implications for fast flow components, water quality and landscape management. J. Hydrol. 285, 76-95. https://doi.org/10.1016/j.jhydrol.2003.08.008.

Caroti, G., Camiciottoli, F., Piemonte, A., Redini, M., 2014. The accuracy analysis of LiDAR-derived elevation data for the geometric description of cross-sections of a riverbed. ISPRS - Int. Arch. Photogramm. Remote Sens. Spat. Inf. Sci. XL-5/W3, 51-57. https://doi.org/10.5194/isprsarchives-XL-5-W3-51-2013.

Cavalli, M., 2013. Semi-automatic derivation of channel network from a high-resolution DTM: the example of an Italian alpine region. Eur. J. Remote Sens. 152-174. https:// doi.org/10.5721/EuJRS20134609.

Cazorzi, F., Fontana, G.D., Luca, A.D., Sofia, G., Tarolli, P., 2013. Drainage network detection and assessment of network storage capacity in agrarian landscape. Hydrol. Process. 27, 541-553. https://doi.org/10.1002/hyp.9224.

Chehata, N., Guo, L., Mallet, C., 2009. Airborne lidar feature selection for urban classification using random forests. Int. Arch. Photogramm. Remote Sens. Spat. Inf. Sci. 38, W8.

Chen, Y., Su, W., Li, J., Sun, Z., 2009. Hierarchical object oriented classification using very high resolution imagery and LIDAR data over urban areas. Adv. Space Res. 43, 1101-1110. https://doi.org/10.1016/j.asr.2008.11.008.

Chen, Z., Gao, B., Devereux, B., 2017. State-of-the-art: DTM generation using airborne LIDAR data. Sensors 17. https://doi.org/10.3390/s17010150.

Chithambaram, R., Beard, K., Barrera, R., 1991. Skeletonizing polygons for map generalization. Technical Papers. Presented at the ACSM-ASPRS Convention, Cartography and GIS/LIS.

Clode, S., Rottensteiner, F., Kootsookos, P.J., 2005. Improving city model determination by using road detection from LIDAR data. In: Presented at the Joint Workshop of ISPRS and DAGM - CMRT05. ISPRS, pp. 159-164.

Dages, C., Voltz, M., Bsaibes, A., Prévot, L., Huttel, O., Louchart, X., Garnier, F., Negro, S., 2009. Estimating the role of a ditch network in groundwater recharge in a Mediterranean catchment using a water balance approach. J. Hydrol. 375, 498-512. https://doi.org/10.1016/j.jhydrol.2009.07.002.

Dietterick, B.C., White, R., Hilburn, R., 2012. Comparing LiDAR-generated to groundsurveyed channel cross-sectional profiles in a forested mountain stream. Albany, CA, pp. 639-648.

Dollinger, J., Dagès, C., Bailly, J.-S., Lagacherie, P., Voltz, M., 2015. Managing ditches for agroecological engineering of landscape. A review. Agron. Sustain. Dev. 35, 999-1020. https://doi.org/10.1007/s13593-015-0301-6.

Doneus, M., 2013. Openness as visualization technique for interpretative mapping of airborne lidar derived digital terrain models. Remote Sens. 5, 6427-6442. https:// doi.org/10.3390/rs5126427.

Duke, G.D., Kienzle, S.W., Johnson, D.L., Byrne, J.M., 2006. Incorporating ancillary data to refine anthropogenically modified overland flow paths. Hydrol. Process. 20, 1827-1843. https://doi.org/10.1002/hyp.5964.

Fischler, M.A., Bolles, R.C., 1981. Random sample consensus: a paradigm for model fitting with applications to image analysis and automated cartography. Commun. ACM 24, 381-395. https://doi.org/10.1145/358669.358692.

Forman, R.T.T., Godron, M., 1986. Landscape Ecology. Wiley, New York.

Hartfield, K.A., Landau, K.I., van Leeuwen, W.J.D., 2011. Fusion of high resolution aerial multispectral and LiDAR data: land cover in the context of urban mosquito habitat. Remote Sens. 3, 2364-2383. https://doi.org/10.3390/rs3112364.

Heipke, C., Mayer, H., Wiedemann, C., Jamet, O., 1997. Evaluation of automatic road extraction. Int. Arch. Photogramm. Remote Sens. 32, 151-160.

Herzon, I., Helenius, J., 2008. Agricultural drainage ditches, their biological importance and functioning. Biol. Conserv. 141, 1171-1183. https://doi.org/10.1016/j.biocon. 2008.03.005.

Höfle, B., Rutzinger, M., 2011. Topographic airborne LiDAR in geomorphology: a technological perspective. Z. Geomorphol. Suppl. Issues 55, 1-29. https://doi.org/10. 1127/0372-8854/2011/0055S2-0043.

Höfle, B., Vetter, M., Pfeifer, N., Mandlburger, G., Stötter, J., 2009. Water surface map ping from airborne laser scanning using signal intensity and elevation data. Earth Surf. Process. Landf. 34, 1635-1649. https://doi.org/10.1002/esp.1853.

Hopkinson, C., Crasto, N., Marsh, P., Forbes, D., Lesack, L., 2011. Investigating the spatial distribution of water levels in the Mackenzie Delta using airborne LiDAR. In: Hydrol. Process.pp. 2995-3011. https://doi.org/10.1002/hyp.8167.

Integraal Waterbeleid, 2014. Toelichting bij de Vlaamse Hydrografische Atlas ten behoeve van de Watertoets.

Joris, I., Feyen, J., 2003. Modelling water flow and seasonal soil moisture dynamics in analluvial groundwater-fed wetland. Hydrol. Earth Syst. Sci. 7, 57-66. https://doi. org/10.5194/hess-7-57-2003.

Koenig, K., Höfle, B., Hämmerle, M., Jarmer, T., Siegmann, B., Lilienthal, H., 2015. Comparative classification analysis of post-harvest growth detection from terrestrial LiDAR point clouds in precision agriculture. ISPRS J. Photogramm. Remote Sens. 104, 112-125. https://doi.org/10.1016/j.isprsjprs.2015.03.003.

Lagacherie, P., Diot, O., Domange, N., Gouy, V., Floure, C., Kao, C., Moussa, R., RobbezMasson, J.M., Szleper, V., 2006. An indicator approach for describing the spatial variability of artificial stream networks with regard to herbicide pollution in cultivated watersheds. Ecol. Ind. 6, 265-279.

Levavasseur, F., Bailly, J.S., Lagacherie, P., Rabotin, M., Colin, F., 2010. Uncertainties of cultivated landscape drainage network mapping and its consequences on hydrological fluxes estimations. In: Accuracy, pp. 153.

Levavasseur, F., Lagacherie, P., Bailly, J.S., Biarnès, A., Colin, F., 2014. Spatial modeling of man-made drainage density of agricultural landscapes. J. Land Use Sci. 1-21. https://doi.org/10.1080/1747423X.2014.884644.

Liimatainen, K., Heikkilä, R., Yli-Harja, O., Huttunen, H., Ruusuvuori, P., 2015. Sparse logistic regression and polynomial modelling for detection of artificial drainage networks. Remote Sens. Lett. 6, 311-320. https://doi.org/10.1080/2150704X.2015. 1031919.

Magirl, C.S., Webb, R.H., Griffiths, P.G., 2005. Changes in the water surface profile of the Colorado River in Grand Canyon, Arizona, between 1923 and 2000: change in profile of the Colorado river. Water Resour. Res. 41. https://doi.org/10.1029/ 2003WR002519.

Malinowski, R., Höfle, B., Koenig, K., Groom, G., Schwanghart, W., Heckrath, G., 2016. Local-scale flood mapping on vegetated floodplains from radiometrically calibrated airborne LiDAR data. ISPRS J. Photogramm. Remote Sens. 119, 267-279. https://doi. org/10.1016/j.isprsjprs.2016.06.009.

Mandlburger, G., Otepka, J., Karel, W., Wagner, W., Pfeifer, N., 2009. Orientation and processing of airborne laser scanning data (OPALS)—Concept and first results of a comprehensive ALS software. Int. Arch. Photogramm. Remote Sens. Spat. Inf. Sci. 38 55-60.

Mandlburger, G., Vetter, M., Milenkovic, M., Pfeifer, N., 2011. Derivation of a countrywide river network based on airborne laser scanning DEMs-results of a Pilot Study. In: MODSIM2011, 19th International Congress on Modelling and Simulation. Modelling and Simulation Society of Australia and New Zealand, December 2011. The Modelling and Simulation Society of Australia and New Zealand Inc., Perth, WA, Australia, pp. 2423-2429.

McFeeters, S.K., 1996. The use of normalized difference water index (NDWI) in the delineation of open water features. Int. J. Remote Sens. 17, 1425-1432.

Menze, B.H., Kelm, B.M., Masuch, R., Himmelreich, U., Bachert, P., Petrich, W., Hamprecht, F.A., 2009. A comparison of random forest and its Gini importance with standard chemometric methods for the feature selection and classification of spectral data. BMC Bioinf. 10, 213. https://doi.org/10.1186/1471-2105-10-213.

Miao, X., Heaton, J.S., Zheng, S., Charlet, D.A., Liu, H., 2012. Applying tree-based ensemble algorithms to the classification of ecological zones using multi-temporal multi-source remote-sensing data. Int. J. Remote Sens. 33, 1823-1849. https://doi. org/10.1080/01431161.2011.602651.

Moussa, R., Voltz, M., Andrieux, P., 2002. Effects of the spatial organization of agricultural management on the hydrological behaviour of a farmed catchment during flood events. Hydrol. Process. 16, 393-412. https://doi.org/10.1002/hyp.333.

Passalacqua, P., Belmont, P., Foufoula-Georgiou, E., 2012. Automatic geomorphic feature extraction from lidar in flat and engineered landscapes: feature extraction in engineered landscapes. In: Water Resour. Res. 48https://doi.org/10.1029/ 2011WR010958. n/a-n/a.

Pedregosa, F., Varoquaux, G., Gramfort, A., Michel, V., Thirion, B., Grisel, O., Blondel, M., Prettenhofer, P., Weiss, R., Dubourg, V., Vanderplas, J., Passos, A., Cournapeau, D., Brucher, M., Perrot, M., Duchesnay, É., 2011. Scikit-learn: machine learning in Python. J. Mach. Learn. Res. 12, 2825-2830.

Petrie, G., 2011. Airborne Topographic Laser Scanners [WWW Document]. <http:// petriefied.info/Petrie_Airborne_Topographic_Laser_Scanners_GEO_1_2011.pdf > .

Podhoranyi, M., Fedorcak, D., 2015. Inaccuracy introduced by LiDAR-generated cross sections and its impact on 1D hydrodynamic simulations. Environ. Earth Sci. 73, 1-11. https://doi.org/10.1007/s12665-014-3390-7.

Rapinel, S., Hubert-Moy, L., Clément, B., Nabucet, J., Cudennec, C., 2015. Ditch network extraction and hydrogeomorphological characterization using LiDAR-derived DTM in wetlands. Hydrol. Res. 46, 276. https://doi.org/10.2166/nh.2013.121.

Roelens, J., Dondeyne, S., Van Orshoven, J., Diels, J., 2016. Extracting cross sections and water levels of vegetated ditches from LiDAR point clouds. Int. J. Appl. Earth Obs. Geoinformation 53, 64-75. https://doi.org/10.1016/j.jag.2016.08.003.

Roelens, J., Rosier, I., Dondeyne, S., Van Orshoven, J., Diels, J., 2018. Extracting drainage networks and their connectivity using LiDAR data. Hydrol. Process. 32, 1026-1037. https://doi.org/10.1002/hyp.11472.

Roub, R., Hejduk, T., Novák, P., 2012. Automating the creation of channel cross section data from aerial laser scanning and hydrological surveying for modeling flood events. J. Hydrol. Hydromech. 60, 227-241. https://doi.org/10.2478/v10098-012-0020-5.

Rouquette, J.R., Posthumus, H., Morris, J., Hess, T.M., Dawson, Q.L., Gowing, D.J.G., 2011. Synergies and trade-offs in the management of lowland rural floodplains: an ecosystem services approach. Hydrol. Sci. J. 56, 1566-1581. https://doi.org/10. 1080/02626667.2011.629785.

Rouse, J.W., Haas, R.H., Schell, J.A., Deering, D.W., 1973. Monitoring vegetation systems in the Great Plains with ERTS. NASA SP-351 I, pp. 309-317.

Sangireddy, H., Stark, C.P., Kladzyk, A., Passalacqua, P., 2016. GeoNet: an open source software for the automatic and objective extraction of channel heads, channel network, and channel morphology from high resolution topography data. Environ. Model. Softw. 83, 58-73. https://doi.org/10.1016/j.envsoft.2016.04.026.

Schechtner, D., 2012. Long-range airborne laser scanner for full waveform analysis LMSQ680i.

Shore, M., Murphy, P.N.C., Jordan, P., Mellander, P.-E., Kelly-Quinn, M., Cushen, M., Mechan, S., Shine, O., Melland, A.R., 2013. Evaluation of a surface hydrological connectivity index in agricultural catchments. Environ. Model. Softw. 47, 7-15. https://doi.org/10.1016/j.envsoft.2013.04.003.

Sofia, G., Prosdocimi, M., Dalla Fontana, G., Tarolli, P., 2014. Modification of artificial drainage networks during the past half-century: evidence and effects in a reclamation area in the Veneto floodplain (Italy). Anthropocene 6, 48-62. https://doi.org/10. 1016/j.ancene.2014.06.005

Vanderstraete, T., 2013. Vlaanderen in 3D: digitaal hoogtemodel Vlaanderen II inwinningsproces en producten [WWW Document]. < https://www.agiv.be/ /media/ 
agiv/producten/dhm-v/documenten/dhmv_ii_inwinning_producten_tv_512juni2013.pdf $>$.

Vercoutere, B., 2014. Doode Bemde en kliniekvijvers. Natuurstudiegroep dijleland.

Wang, C., Hu, F., Sha, D., Han, X., 2017. Efficient LiDAR point cloud data managing and processing in a hadoop-based distributed framework. ISPRS Ann. Photogramm. Remote Sens. Spat. Inf. Sci. IV-4/W2, 121-124. https://doi.org/10.5194/isprs-
annals-IV-4-W2-121-2017.

Weinmann, M., 2016. Reconstruction and Analysis of 3D Scenes. Springer International Publishing, Cham.

Yokoyama, R., Shirasawa, M., Pike, R.J., 2002. Visualizing topography by openness: a new application of image processing to digital elevation models. Photogramm. Eng. Remote Sens. 68, 257-266. 